\title{
Polyphenolic characterization of pollen grains of some medicinal plant species using Ultra High Performance Liquid Chromatography (UHPLC)
}

\author{
Rajwant Kaur \\ Department of Botanical and Environmental Sciences, Guru Nanak Dev University, Amritsar - \\ 143005 (Punjab), India \\ Manpreet Kaur \\ Department of Human Genetics, Guru Nanak Dev University, Amritsar-143005 (Punjab), India \\ Avinash Kaur Nagpal \\ Department of Botanical and Environmental Sciences, Guru Nanak Dev University, Amritsar - \\ 143005 (Punjab), India \\ Jatinder Kaur Katnoria* \\ Department of Botanical and Environmental Sciences, Guru Nanak Dev University, Amritsar - \\ 143005 (Punjab), India \\ *Corresponding author. Email: jkat08@yahoo.com
}

\section{Article Info}

https://doi.org/10.31018/ jans.v13i3.2737

Received: May 27, 2021

Revised: July 28, 2021

Accepted: August 3, 2021

\section{How to Cite}

Kaur, R. et al. (2021). Polyphenolic characterization of pollen grains of some medicinal plant species using Ultra High Performance Liquid Chromatography (UHPLC). Journal of Applied and Natural Science, 13(3), 840 - 845. https://doi.org/10.31018/ jans.v13i3.2737

\begin{abstract}
Polyphenols, the secondary metabolites distributed in different parts of a plant, have major role in protecting the plants from deleterious effects of ultraviolet radiations and various diseases caused by pathogens. Considering the fact that these metabolites possess tremendous medicinal properties, extensive research has been carried out during the past few decades to explore their potential health benefits. Further, polyphenols are documented to possess different activities such as antioxidant, anticarcinogenic, anti-inflammatory, antimicrobial and antiulcer. The present study pertained to analyze different polyphenolic compounds in pollen grains of 9 medicinally important plant species viz., Bauhinia variegata, B.purpurea, Cassia biflora, C. fistula, C. glauca, C. saimea and Delonix regia belonging to Fabaceae family, Hibiscus rosa-sinensis belonging to Malvaceae family and Melia azadirach belonging toMeliaceaefamily using Ultra high-performance liquid chromatography (UHPLC). Various polyphenolic compounds likecaffeic acid, catechin, chlorogenic acid, coumaric acid, ellagic acid, epicatechin, gallic acid, kaempferol, quercetin, rutin, tert-butyl hydroquinone andumbelliferonewere found to be present in the pollen grains of these plant species. The order of plant species in terms of maximum number of polyphenolic compounds was observed as Cassia saimea $(10)>B$. purpurea $(9)=$ C. fistula $(9)=$ Hibiscus rosa-sinensis $(9)>$ Delonix regia $(8)>B$. variegata $(6)>C$. glauca $(4)=$ Melia Azadirach (4) > C. biflora (3). The plants such as C. saimea, B. purpurea, C. fistula and $H$. rosa-sinensis with different polyphenolic compounds indicated their potential forthe treatment of ailments.
\end{abstract}

Keywords: Catechin, Fabaceae, Phytoconstituents, Pollen grains, Polyphenols

\section{INTRODUCTION}

Oxidative modification of the biomolecules such as carbohydrates, deoxyribonucleic acid (DNA), lipids, proteins and ribonucleic acid (RNA) by reactive oxygen species (ROS) results in the occurrence of a wide range of diseases, including cancer. Plants possess secondary metabolites such as polyphenols, alkaloids, saponins and terpenoids that play an important role in scavenging the reactive oxygen species, thus providing protection against various diseases (Govindarajan et al., 2005; Kaur et al., 2005; Valko et al., 2007; Zahin et al., 2014). The exploration of different compounds from the whole plant or any part of the plant possessing antioxidant, antimutagenic and anticancer properties is now a new area of research. Among different parts of plants, exploration of pollen grains for different bioactivities has gained attention due to their several therapeutic properties. Pollen grains, the male gametophytes of flowers, contain various phytoconstituents, including carbohydrates, amino acids, lipids, vitamins, minerals and polyphenols. These phytoconstituents, apart from contributing towards the nutrition value of the pollen grains possess medicinal properties to cure various 
ailments viz.,cold, flu, ulcers, premature ageing, anemia, allergic reactions, enteritis, chronic prostatitis and colitis (Carpes et al., 2007; Saric et al., 2009; Graikou et al., 2011; Kao et al., 2011; Barbieri et al., 2020; Puscion et al., 2020; Thakur and Nanda, 2021).

Among different phyto-constituents, polyphenols are widely distributed in different parts of plants thatcontribute towards various therapeutic properties such as antineoplastic, antidiarrhoeic andantioxidant (Bonvehi et al., 2001; Almaraz-Abarca et al., 2007; Freire et al., 2012). A number of studies have shown the presence of polyphenols in pollen grains of different plant species (Carpes et al., 2007; Almaraz-Abarca et al., 2007; Freire et al., 2012; Leja et al., 2007; Basuny et al., 2013). Bonvehi et al. (2001) analyzed 11 honey bee samples with pollens collected from Western Spain for contents of polyphenols, flavonoids and free flavonoid aglycon compounds. During the study, 15 flavonoids were reported to range from $0.35-0.76 \mathrm{~g} / 100 \mathrm{~g}$, while total free aglycons ranged from $45.73-82.41 \mathrm{mg} / 100 \mathrm{~g}$. Almeida-Muradian et al. (2005) explored dried bee pollen pellets collected from South region of Brazil forthe contents of moisture, ash, lipids, proteins, total carotenoids, beta-carotene and vitamin C. Average contents of protein, moisture, lipids and ash were found to be 20 $\%, 7.4 \%, 6 \%$ and $2.2 \%$, respectively. The carotenoid content was found to be $76.33 \mu \mathrm{g} / \mathrm{g}$ of the sample, while vitamin $C$ and $\beta$-carotene were absent in samples. Pachthong et al. (2006) reported two bioactive brassinosteroids from the pollen grains of pumpkin (Cucurbita moschata) collected from Mae-Ai district, Chiang Mai, Thailand using gas chromatography mass spectroscopy (GC-MS).

Leja et al. (2007) studied different phenolic constituents of bee pollen containing pollen of 12 plant species viz., Sinapis alba, Phacelia tanacetifolia, Robinia pseudoacacia, Aesculus hippocastanum, Taraxacum officinale, Malus domestica, Pyrus communis, Trifolium sp., Lamium purpureum, Lupinu spolyphyllus, Chamerion angustifolium and Zea mays collected from Krakow, Poland. The samples were analyzed for different phenolic constituents and the study revealed the presence of total phenols, phenylpropanoids, flavonols and anthocyanins. Kao et al. (2011) collected pollen of tea (Camellia sinensis) from Western regions of Taiwan and analyzed for content of total polyphenols. Different pollen extracts were prepared using $50 \%$ ethanol, 95 $\%$ ethanol, hot water and cold water. The study revealed that ethanolic extracts possessed more phenolic compounds as compared to aqueous extracts. Cosmulescu et al. (2015) determined the total phenolic, flavonoids and mineral contents and antioxidant activities of methanolic extracts of pollen of 3 walnut genotypes collected from South Western Romania.

The research, in recent years, is mainly focused on the anticarcinogenic, anti-inflammatory, antibacterial, anti- oxidant, antiallergic, antiviral, estrogenic and antiulcer properties of these compounds (Kao et al., 2011; Bonvehi et al., 2001; Kroyer and Hegedus, 2001; Munoz et al.,2020). Considering the same, the pollen extracts of 9 plant species viz., Bauhinia variegata, $B$. purpurea, Cassia biflora, C. fistula, C. glauca, $C$. saimea, Delonix regia, Hibiscus rosa-sinensis and Melia azadirach were screened for the presence of different polyphenolic compounds and their concentration. Different plant parts viz., leaves, bark, root, flowers and stamens of these plants are well documented to contain many active phytoconstituents (Balamurugun and Muralidharan, 2010; Kumar and Chandrshekar, 2011; Veerachari and Bopaiah, 2012; Majji et al., 2013; Dahiru et al., 2013; Mariarjancyrani et al., 2013; Bansal et al.,2014; Thakur et al., 2016), so far, no report is available on the chemical composition of pollen grains of these plant species under study except for amino acids (Kaur et al., 2015).

\section{MATERIALS AND METHODS}

\section{Plant species}

The pollen grains of 9 plant species viz., Bauhinia variegata, B. purpurea, Cassia biflora, C. fistula, C. glauca, C. saimea, Delonix regia, Hibiscus rosa-sinensis and Melia azadirach were collected from the Guru Nanak Dev University campus and were analyzed for the presence of different polyphenolic compounds.

\section{Collection of pollen grains samples}

Fresh flowers (just prior to anthesis) of all plant species were collected from Guru Nanak Dev University campus, Amritsar, Punjab (India). For the collection of pollen grains, anthers from each species were removed from the flowers, teased with the help of sharp forceps and tapped in a pre-weighed butter paper to collect pollen grains. The anthers of each species tapped in individual butter paper using 100-150 flowers (per species) to obtain approximately $1 \mathrm{~g}$ of pollen grains. The pollen grains thus obtainedwere further used for the preparation of extracts.

\section{Preparation of pollen extracts}

Ethanolic extracts of pollen grains of different plant species were prepared following the protocol of Carpes et al. (2007) with few modifications. $7.5 \mathrm{ml}$ of $70 \%$ ethanol was added to $1 \mathrm{~g}$ of pollen grains and kept at $70{ }^{\circ} \mathrm{C}$ for $1 \mathrm{~h}$ with shaking for $1 \mathrm{~min}$ after every $10 \mathrm{~min}$ interval. The supernatant was pipetted out and the solid residue was re-extracted with $7.5 \mathrm{ml}$ of $70 \%$ ethanol. The process was repeated 3 times and the supernatants were pooled and the final volume made to $20 \mathrm{ml}$.

\section{Analysis of polyphenols}

The extracts were run through Ultra high-performance 
liquid chromatography (UHPLC) and different polyphenolic compounds were identified and quantified (Model: Nexera, Make: Shimadzu). The separation of different polyphenolic compounds were carried out using $\mathrm{C} 18$ column $(150 \times 4.6 \mathrm{~mm}, 5 \mu \mathrm{m}$ particle size $)$ at $25{ }^{\circ} \mathrm{C}$. The flow rate was set at $1.8 \mathrm{ml} / \mathrm{min}$ and injection volume used was $50 \mu$ l.

\section{Statistical analysis}

Pearson correlation was used to find out the correlation between polyphenols of various plant species. The software used for correlation analysis was Statistical Package for the Social Sciences (SPSS-2015).

\section{RESULTS AND DISCUSSION}

Pollen grains possess several active constituents such as polyphenols, terpenoids, carotenoids and steroids. The use of apicultural products to cure many diseases or natural diet supplements has gained lots of interest in past decades. Many investigations were observed to be focused on the exploration of active constituents of pollen grains during the study (Bonvehi et al., 2001; Almeida-Muradiana et al., 2005; Almaraz-Abarca et al., 2007; Balamurugun and Muralidhran, 2010; Kao et al., 2011; Barbieri et al., 2020; Puscion et al., 2020; Thakur and Nanda, 2021). The antioxidant related activity of different polyphenolic compounds in pollen grains is also well documented (Carpes et al., 2007; Kao et al., 2011; Leja et al., 2007; Lee et al., 2009). Different polyphenolic compounds viz., caffeic acid, catechin, chlorogenic acid, coumaric acid, ellagic acid, epicatechin, gallic acid, kaempferol, quercetin, rutin, tert-butyl hydroquinone and umbelliferone were observed to be present in the pollen grains of plants during present study. However, only catechin was found to be present in all species.

Different plant species under the present study quantitatively contained polyphenols in their pollen grains as 10 (Cassia saimea: catechin, epicatechin, caffeic acid, chlorogenic acid, coumaric acid, umbelliferone, ellagic acid, gallic acid, tert-butyl hydroquinone); 9 (Bauhinia purpurea: catechin, epicatechin, umbelliferone, caffeic acid, chlorogenic acid, coumaric acid, ellagic acid, gallic acid, tert-butyl hydroquinone); 9 (C. fistula; catechin, epicatechin, kaempferol, quercetin, rutin, umbelliferone, coumaric acid, ellagic acid, tert-butyl hydroquinone); > 9 (Hibiscus rosasinensis; catechin, kaempferol, quercetin, umbelliferone, caffeic acid, chlorogenic acid, coumaric acid, gallic acid, tert-butyl hydroquinone); > 8 Delonixregia; catechin, kaempherol, rutin, umbelliferone, chlorogenic acid, coumaric acid, gallic acid, ellagic acid); > 6 (Bauhinia variegata; catechin, epicatechin, umbelliferone,coumaric acid, ellagic acid, tert-butyl hydroquinone); > 4 (C. glauca; catechin, epicatechin, umbelliferone coumaric acid, gallic acid, tert-butyl hydro- quinone); > 4 (Melia azadirach; catechin, kaempherol, quercetin, gallic acid); > 3 (C. biflora; catechin, chlorogenic acid, gallic acid) as shown in Table 1. Various environmental factors like sun exposure, soil type, rainfall, plant nutrition etc., affect the polyphenol content in plants(Pandey and Rizvi, 2009).

Polyphenolic compounds are mainly categorized into two groups viz., flavonoids and phenolic acid. Flavonoids contain two or more aromatic rings and are further subdivided into flavones, isoflavones, isoflavanes, flavanones, flavonols, anthocyanidins, chalcones and dihydrochalcones, while phenolic acid contains a phenolic ring and an organic carboxylic acid and are further subdivided into hydrobenzoic acid and hydrocinnamic acid (Kao et al., 2011; Almeraz-Abarca et al., 2007). Almaraz-Abarca et al. (2007) reported that flavonol and phenolic acids were the main classes of polyphenols present in the pollen grains of Prosopis juliflora. Seven phenolic acid viz., caffeic acid, chlorogenic acid, coumaric acid, ellagic acid, gallic acid,tert-butyl hydroquinone and umbelliferone were analyzed during the study. Among 9 plant species studied, caffeic acid was present only in three plant samples viz., Bauhinia purpurea, Cassia saimea and Hibiscus rosa-sinensis gallic acid were present in all the sample except Bauhinia variegata and Cassia fistula. Different flavonols viz., kaempferol, quercetin and rutin were analyzed in the pollen grains of different plant species.

Many reports are available for different bioactivities of the polyphenolic compounds. Zahin et al. (2014) reported two polyphenolic compounds viz., penicalagin and ellagic acid, extracted from fruit peel of Punica granatum, showed antimutagenicity and resulted in inhibition of DNA adducts formation induced by benzo (a)pyrene. Smerak et al. (2002) evaluated the antimutagenic activity of ellagic acid following Ames assay. Gallic acid was reported for its anti-neoplastic activity and antifungal activity of leaf extract of Toona sinensis (Chia et al., 2010; Hong et al., 2011), while rutin, extracted from Tobacco leaves, was reported for its antifungal, antibacterial, anthelmintic, larvicidal and cytotoxicity (Dubey et al., 2014). Geetha et al. (2004) reported the quercetin had antioxidant and antimutagenic potential. The auto-oxidation of quercetin resulted in the production of hydroxyl radicals within the cells responsible for antiproliferative and antimutagenicity. Rho et al. (2011) reported the depigmenting and antiinflammatory response of Kaempferol isolated from Hibiscus cannabinus.

Pearson correlation showed the presence of a positive correlation between gallic acid and rutin at $5 \%$ level of significance (Table 2). Rutin is known as an important phyto-antioxidant and plays an important role in improving blood circulation, so it is used to treat haemorrhoids, varicosis and microangiopathy (Ugusmanet al., 2014), while gallic acid is well known to inhibit amyloid 


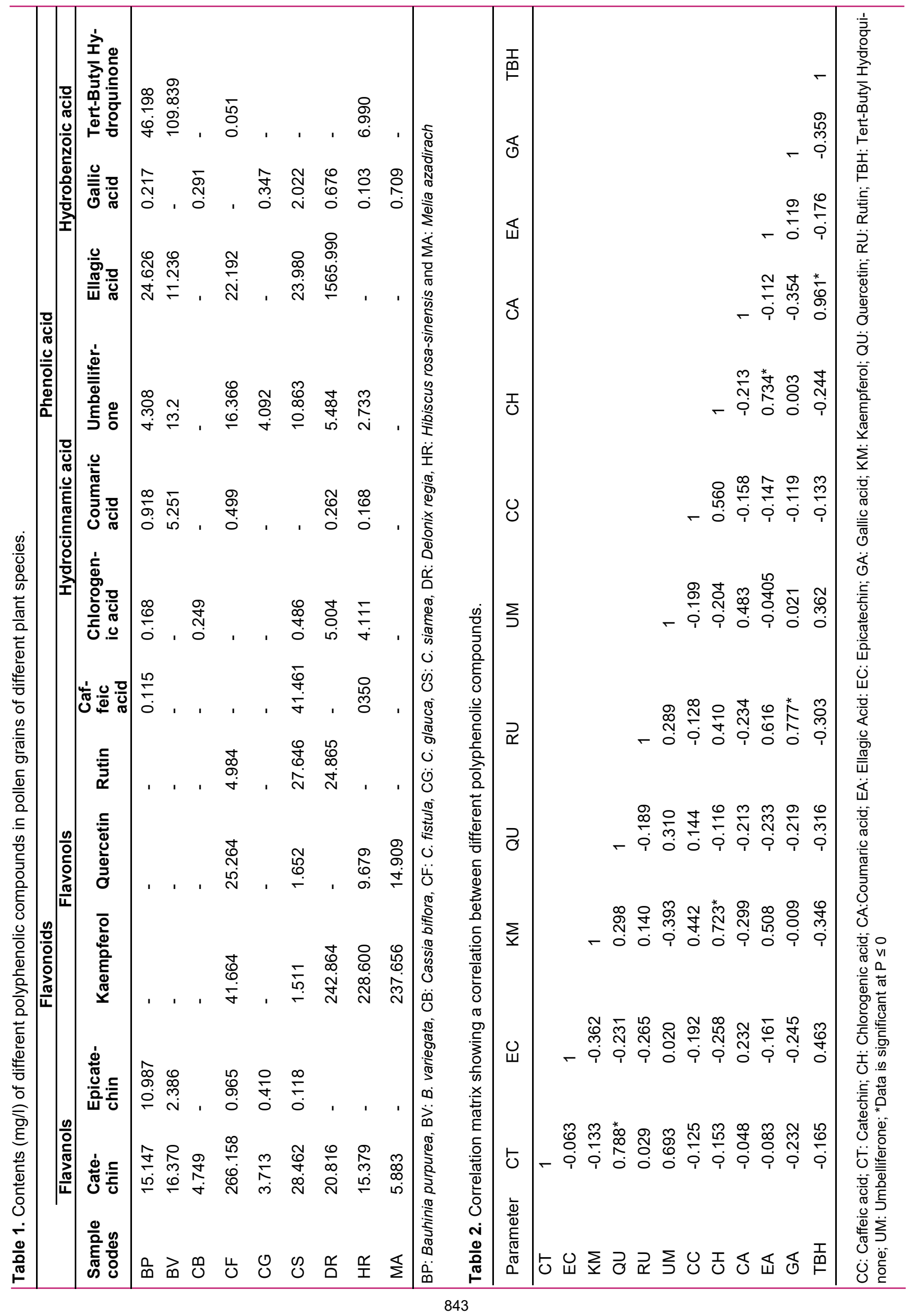


fibrils. A positive correlation existed between quercetin and catechin (as shown in Table 2). Pignatelli et al. (2000) reported that both compounds have a tendency to inhibit collagen-induced hydrogen peroxide production and calcium mobilization and 1,3,4-inositol triphosphate formation in combination. In the present study, positive correlation is existed between kaempferol and chlorogenic acid at $5 \%$ level of significance. Chlorogenic acid has shown anti-oxidative and antihypertensive effects (Zhao et al., 2011) while kaempferol has been documented to have anticancer, antidiabetic, antiviral and antioxidant effects. Ellagic acid also showed a significant correlation with rutin. The present study showed that coumaric acid showed a strong positive correlation with Tert-Butyl Hydroquinone. Both coumaric acid and Tert-Butyl Hydroquinone have antioxidant effects. Polyphenol umbelliferon were documented to be used as a sun screen agent due to its ultraviolet radiation protective activity (Lou et al., 2010). Different polyphenols are consumed as dietary supplements or obtained from foodstuffs such as fruit and vegetables due to their properties to reduce incidences of heart disease, cancer, gastrointestinal and neurological diseases, liver diseases, atherosclerosis, obesity and allergies.

\section{Conclusion}

Polyphenols are considered to be potent antioxidants that protect the different biomolecules such as DNA, RNA, proteins, lipids and carbohydrates from oxidative stress. In the present study, various polyphenolic compounds viz., caffeic acid, catechin, chlorogenic acid, coumaric acid, ellagic acid, epicatechin, gallic acid, kaempferol, quercetin, rutin, tert-butyl hydroquinone and umbelliferonewere found to be present in pollen grains of 9 plant species. As all polyphenols are well documented for their bioactivities, the present study would be very useful in the field of pharmaceuticals.

\section{ACKNOWLEDGEMENTS}

The authors are thankful to the University Grant Commission, New Dehli, for providing finical assistance under Maulana Azad National Fellowship (MANF) to Rajwant Kaur and Department of Emerging Life Sciences, Guru Nanak Dev University, Amritsar for providing necessary facilities.

\section{Conflict of interest}

The authors declare that they have no conflict of interest.

\section{REFERENCES}

1. Almaraz-Abarcaa, N., Campos, M.G., Avila-Reyesa, J.A.,
Naranjo-Jimeneza, N., Corrala, J.H. \& Gonzalez-Valdez, L.S. (2007). Antioxidant activity of polyphenolic extract of monofloral honey bee collected pollen from mesquite (Prosopis juliflora, Leguminosae). Journal of Food Composition and Analysis. 20,119-124.

2. Almeida-Muradiana, L.B., Pamplonaa, L.C., Coimbraa, S. \& Barth, O.M. (2005). Chemical composition and botanical evaluation of dried bee pollen pellets. Journal of Food Composition and Analysis. 18,105-111.

3. Balamurugan, G. \& Muralidharan, P. (2010). Antiobesity effect of Bauhinia variegata bark extract on female rats fed on hypercaloric diet. Bangladesh Journal of Pharmacology. 5,8-12.

4. Bansal, V., Malviya, R. \& Deeksha. (2014). Phytochemical, pharmacological profile and commercial utility of tropically distributed plant Bauhinia variegata. Global Journal of Pharmacology. 8,196-205.

5. Barbieri, D., Gabriele, M., Summa, M., Colosimo, R., Leonardi, D., Domenici, V. \& Pucci L. (2020). Antioxidant, nutraceutical properties and fluorescence spectral profiles of bee pollen samples from different botanical origins. Antioxidants 2020;doi:10.3390/antiox9101001.

6. Basuny, A.M., Arafat, S.M. \& Soliman, H.M. (2013). Chemical analysis of olive and palm pollen: Antioxidant and antimicrobial activation properties. Wudpecker Journal of Food Technology. 1,14-21.

7. Bonvehi, S., Torrento, S.M. \& Lorente, C.E. (2001). Evaluation of polyphenolic and flavonoid compounds in honeybee-collected pollen produced in Spain. Journal of Agricultural and Food Chemistry. 49,1848-1853.

8. Carpes, S.T., Begnini, S.T., Alencar, R.\&Masson, S.M. (2007). Study of preparations of bee pollen extracts, antioxidant and antibacterial activity. Ciencia e Agrotecn. 31,1818-1825.

9. Chia, Yi-Chen., Rajbanshi, R., Calhoun, C., Robert, H. \& Chiu. (2010). Anti-neoplastic effects of gallic acid, a major component of Toona sinensis leaf extract, on oral squamous carcinoma cells. Molecules. 15,8377-8389.

10. Cosmulescu, S., Trandafir, I. \& Nour, V. (2015). Chemical composition and antioxidant activity of walnut pollen samples. NotulaeBotanicaeHortiAgrobotanici. 43,361-365.

11. Dahiru, D., Malgwi, A.R.\& Sambo, H.S. (2013). Growth inhibitory effect of Senna siamea leaf extracts on selected microorganisms. American Journal of the Medical Sciences. 3,103-107

12. Dubey, S., Ganeshpurkar, A., Bansal, D. \& Dubey, N. (2014). Experimental studies on bioactive potential of rutin. Chronicles of Young Scientists. 4,153-157.

13. Freire, K.R.L., Lins, A.C.S., Dórea, M.C., Santos, F.A.R., Camara, C.A. \& Silva, T.M.S. (2012). Palynological origin, phenolic content, and antioxidant properties of honeybeecollected pollen from Bahia, Brazil. Molecules. 17,16521664.

14. Geetha, T., Malhotra, V., Chopra, K. \& Kaur, I.P. (2004). Antimutagenic and antioxidant/prooxidant activity of quercetin. Indian Journal of Experimental Biology. 43,61-67.

15. Govindarajan, R., Vijayakumar, M. \& Pushpangadan, P. (2005). Antioxidant approach to disease management and the role of "Rasayana" herbs of Ayurveda. Journal of Ethnopharmacology. 99,165-178.

16. Graikou, K., Kapeta, S., Aligiannis, N., Sotiroudis, G., Chondrogianni, N., Gonos, E. \& Chinou, I. (2011). Chemi- 
cal analysis of Greek pollen - Antioxidant, antimicrobial and proteasome activation properties. Central Journal, 5, $33-41$.

17. Hong, L.S., Ibrahim, D., Kassim, J. \& Sulaiman, S. (2011). Gallic acid: An anticandidal compound in hydrolysable tannin extracted from the barks of Rhizophora apiculataBlume. Journal of Applied Pharmaceutical Science, 1, 7579.

18. Kao, Y., Lu, M. \& Chen C. (2011). Preliminary analyses of phenolic compounds and antioxidant activities in tea pollen extracts. Journal of Food and Drug Analysis, 19,470477.

19. Kaur, R., Nagpal, A. \& Katnoria, J.K. (2015). Amino acids composition of pollen grains of some medicinally important plant species. Journal of Chemical and Pharmaceutical Research, 7,122-127.

20. Kaur, S., Michael, H., Arora, S., Harkonen, P.L. \& Kumar, S. (2005). The in vitro cytotoxic and apoptotic activity of Triphala- an Indian herbal drug. Journal of Ethnopharmacology, 97,15-20.

21. Kroyer, G \& Hegedus, N. (2001). Evaluation of bioactive properties of pollen extracts as functional dietary food supplement. Innovative Food Science and Emerging Technologies, 2,171-174.

22. Kumar, S. \& Chandrshekar, K.S. (2011). Bauhinia purpurea Linn.: A review on its ethanobotany, phytochemical and pharmacological profile. Research Journal of Medicinal Plants, 5, 420 - 431.

23. Lee, K.H., Kim, A.J. \& Choi, E.M. (2009). Antioxidant and antiinflammatory activity of pine pollen extract in vitro. Phytotherapy Research, 23, 41-48.

24. Leja, M., Mareczek, A., Wyzgolik, G., Klepacz-Baniak, J. \& Czekonska, K. (2007). Antioxidative properties of bee pollen in selected plant species. Food Chemistry, 100,237 -240 .

25. Lou, Z., Wang, H., Li, J., Chen, S., Zhu, S., Ma C. \& Zhouping, W. (2010). Antioxidant activity and chemical composition of the fractions from burdock leaves. Journal of Food Science, 75,413-419.

26. Majji, L.N., Battu, G.R., Jangit, R.K. \& Talluri, M.R. (2013). Evaluation of in-vitro antibacterial activity of Cassia siamea leaves. International Journal of Pharmacy and Pharmaceutical Sciences. 5,263-265

27. Mariajancyrani, J., Chandramohan, G., Saravanan, P. \& Saivaraj, S. (2013). In-Vitro Antioxidant Potential of Delonix regia Leaves. Scholars Academic Journal of Pharmacy, 2, $468-471$.

28. Munoz, E., Velásquez, P., Rodriguez, K., Montenegro, G. \& Giordano, A. (2020). Influence of Brassica campestris and Galega officinalis on Antioxidant Activity of Bee Pollen. RevistaBrasileira de Farmacognosia, 30,444449.

29. Pachthong, C., Supyen, D., Buddhasukh, D. \& Jatisatienr, A. (2006). Isolation and characterization of brassinolide and castasterone in the pollen of Pumpkin Chiang Mai. Journal of Science, 33,95-101.

30. Pandey, K.B. \& Rizvi, S. I. (2009). Plant polyphenols as dietary antioxidants in human health and disease. Oxida- tive Medicine and Cellular Longevity, 2, 270-278.

31. Pignatelli, P., Pulcinelli, F.M., Celestini, A., Lenti, L., Ghiselli, A., Gazzaniga, P.P. \& Violi, F. (2000). The flavonoids quercetin and catechin synergistically inhibit platelet function by antagonizing the intracellular production of hydrogen peroxide. American Journal of Clinical Nutrition, 72,1150-1155

32. Puscion-Jakubik, A., Borawska, M.A. \& Socha, K. (2020). Modern methods for assessing the quality of bee honey and botanical origin identification. Foods, 2020;doi:10.3 390/foods 90810 .

33. Rho, H.S., Ghimeray, A.K., Yoo, D.S., Ahn, S.M., Kwon, S.S., Lee, K.H., Cho, D.H. \& Cho, J.Y. (2011). Kaempferol and kaempferol rhamnosides with depigmenting and antiinflammatory properties. Molecules, 16, 3338 - 3344.

34. Saric, A., Balog, T., Sobocanec, L., Kusic, B., Sverko, V., Rusak, G., Likic, S., Bubalo, D., Pinto, B., Reali, D. \& Marotti T. (2009). Antioxidant effects of flavonoid from Croatian Cystusincanus L. rich bee pollen. Food and Chemical Toxicology, 47, 547 - 554.

35. Smerak, P., Sestakova, H., Polivkova, Z., Barta, I., Turek, B., Bartova, J., Langova, M. \&Andel M. (2002). Antimutagenic effect of ellagic acid and its effect on the immune response in mice. Czech Journal of Food Science, 20,181 $-191$.

36. Thakur, M. \& Nanda, V. (2021). Screening of Indian bee pollen based on antioxidant properties and polyphenolic composition using UHPLC-DAD-MS/MS: A multivariate analysis and ANN based approach. Food Research International, 140,110-141.

37. Thakur, M., Asrani, R.K., Thakur, S., Sharma, P.K., Patil, R.D., Lal, B. and Parkash, O. (2016). Observations on traditional usage of ethnomedicinal plants in humans and animals of Kangra and Chamba districts of Himachal Pradesh in North-Western Himalaya, India. Journal of Ethnopharmacology, 191, 280-300. https://doi.org/10.1016/ j.jep.2016.06.033

38. Ugusman, A., Zakaria, Z., Chua, K.H., Anita, N., Nordin, M.N. \& Mahdy, Z.A. (2014). Role of rutin on nitric oxide synthesis in human umbilical vein endothelial cells.Scientific World Journal, 1-9.

39. Valko, M., Leibfritz, D., Moncol, J., Cronin, M.T.D., Mazur, M. \& Telser, J. (2007). Free radicals and antioxidants in normal physiological functions and human disease. International Journal of Biochemistry and Cell Biology, 39, 4484.

40. Veerachari, U \& Bopaiah, A.K. (2012). Phytochemical investigation of the ethanol, methanol and ethyl acetate leaf extracts of six Cassia species. InternationalJournal of Pharma and Bio sciences, 3, 260-270.

41. Zahin, M., Ahmad, I., Gupta, R.C. \& Aqil, F. (2014). Punicalagin and ellagic acid demonstrate antimutagenic activity and inhibition of benzo[a]pyrene induced DNA adducts. BioMed Research International,1-10.

42. Zhao, Y., Wang, J., Ballevre, O., Luo, H.\& Zhan, W. (2011). Antihypertensive effects and mechanisms of chlorogenic acids. Hypertension Research, 2011,1-5. 